\title{
THE POSSIBILITY OF USING REMOTE SENSING IN STUDYING PIGMENTS OF OAK TREE (QUERCUS AEGILOPS) IN PIRMUS AREA
}

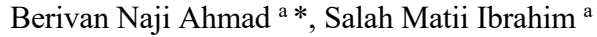

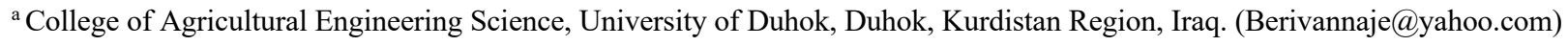

\begin{abstract}
:
Hyperspectral remote sensing (HRS) is one of the advanced technologies which began in the early 1980s. It is one of the most significant breakthroughs in remote sensing. It emerged as a promising technology for studying earth's surface materials in two ways spectrally \& spatially. This technology is developed by breaking a broad band from the visible and infra-red spectrum into hundreds of spectral parts to obtain geochemical information from inaccessible planetary surfaces. The ample spectral information provided by hyperspectral data can identify and distinguish spectrally similar materials that enhance the capability of detecting various ground objects in detail. 28 Oak trees (Quercus aegilops) from the village of pirmus/ Duhok were selected to study the possibility of using hyper spectroscopy in studying chlorophyll a and chlorophyll b (Chla, Chlb). The site of the study has four main slope aspects SWNE (south, west, north and, east), seven trees from each of them were used for collecting leave samples. Two mature and healthy leaves samples were collected from the top of each tree and sealed in polyethylene bags and stored in an ice cooler. Laboratory reflectance spectra were acquired for each leave sample from 350 to $2500 \mathrm{~nm}$ by using the Analytical Spectral Device (ASD) spectroradiometer. A $0.25 \mathrm{gm}$. from each leave was dissolved in ethanol to extract (Chla, Chlb). Then, total chlorophyll $(\mathrm{Chl})$ content was measured at $649 \& 665 \mathrm{~nm}$ by using the $6705 \mathrm{UV} / \mathrm{VIS}$ spectrophotometer.

Results show that the mean value of the entire Chl was $18.96681 \mathrm{mg} / \mathrm{gm}$. Also, the correlation coefficient $\left(\mathrm{R}^{2}\right)$ of Chla (at $\left.665 \mathrm{~nm}\right)$ and Chlb (at $649 \mathrm{~nm}$ ) show a moderately strong relationship between the variables $(73.165,48.089)$ alternatively, also the standard errors were close to zero $(0.0913355$ and 0.0512682$)$. The $\mathrm{R}^{2}$ of Chla for the four slope aspects NESW (North, East, South, and West) were $34.112,79.805,94.113$ and 82.8547 alternatively. Also, the $\mathrm{R}^{2}$ of Chlb for the same four slope aspects was 49.498 , $63.25,76.99$ and 74.34 alternatively. All the results in both bands at least show strong relationships between the variables except for the north slope aspect which shows less $\mathrm{R}^{2}$ values (34.112and 49.498). This is because the sun is facing the south slope along all day hours, while there is no direct light facing the north aspect along the day which is directly related to the zenith angle (at the $36 \mathrm{~N}$ latitude which is about $76.5 \mathrm{deg}$.). For this reason, the north slope aspect $\mathrm{R}^{2}$ bias the overall $\mathrm{R}^{2}$ of the 28 trees. The statistical analysis shows that all of the standard error values of Chla and Chlb for the four slope aspects NESW were $(0.143789,0.0685267$, $0.0419621,0.100696),(0.0222774,0.0235722,0.028614$, and 0.0161366$)$ alternatively, which indicates that the predicted values (reflectivity values) are close to the real values (chemical analysis values). From the current results, it is very obvious that the ASD Field Spec 3 spectroradiometer is quite an efficient and un destructive tool that can be used for Quercus Aegilops chlorophyll estimation at 665 and $649 \mathrm{~nm}$. Also, the instrument shows the capability of distinguishing the differences in leaf chlorophyll content among the different slope aspects in both bands.
\end{abstract}

KEYWORDS: Hyperspectral, ASD Field Spec, Quercus Aegilops, Chlorophyll, Slope Aspects.

\section{INTRODUCTION}

The advanced remote sensing technique is of growing interest to the remote sensing community (Marcus Bo., et.al, 2008). Hyperspectroscopy has the capacity of slicing the electromagnetic spectrum into hundreds of narrow spectral bands and enabling to extract diagnostic spectral features that are unique absorption bands in $20-40 \mathrm{~nm}$ for most natural materials (Marcus Bo., et.al, 2008) The most important application fields for hyperspectral remote sensing can be found in plant and plant ecosystems because there are many unique diagnostic absorption features (bands) in the 0.4 to 2.5 $\mu \mathrm{m}$ spectral range $(\mathrm{Pu}, 2017)$. Hyperspectral data were applied in vegetation, soils, geology, atmospheric science, ecosystem, and oceanography hydrology since the early 1980s (Goetz et al. 1985).

Because of their clear absorption bands in the blue and red light (Researchgate, 2016), plant pigments including chlorophylls, carotenoids, and anthocyanins, can readily be assessed with spectral reflectance because these pigments are optically detectable and serve either photosynthetic or photoprotective functions. They also provide an accessible 'handle' for evaluating the relative photosynthetic activity which can vary with leaf type (Gamon et al., 1997).

The chlorophylls are the most important organic molecules in the earth and it is argued for that as they are necessary for photosynthesis. For plant and mammal survival through their photosynthetic and nutritional functions, the carotenoids are essential. However, other pigment groups are the key to the plant physiology and the organisms with which they interact (Davies, 2004). Chlorophylls give an indirect estimation of the nutrient status because most of the leaf nitrogen is incorporated in chlorophyll (Filella, I et al, 1995). Furthermore, leaf chlorophyll content is indicative and closely related to plant stress and senescence (Hendry, et al., 1987) and (Merzlyak, et al., 1999).

Croft et al. at 2017 found that $\mathrm{Chl}$ a and $\mathrm{Chl} b$ absorb sunlight at different wavelengths (Chla mainly absorbs red-orange light

* Corresponding author

This is an open access under a CC BY-NC-SA 4.0 license (https://creativecommons.org/licenses/by-nc-sa/4.0/) 
and Chlb mainly absorbs blue-purple light), leading to the assumption that the total amount of leaf chlorophyll content $(\mathrm{Chl} \mathrm{a}+\mathrm{b})$ directly influences the photosynthetic capacity of plants (Li Y, and et al, 2018).

The factors affecting leave chlorophyll contents are latitudes (sun angle), hours of direct sunlight, slope aspect, climate \& microclimate (temperature, humidity), soil (especially the $\mathrm{PH}$, moisture and $\mathrm{N}$ and $\mathrm{P}$ content) and daily cycle of solar radiation received at different times of the year (Fredeen et al., 1990, Nagata et al., 2005, Rosenberg et al. 1983, Wolken et al., 1955, Zhou, 2003).

The objectives of this study are 1- Determining the efficiency of using the spectroradiometer in studying Chla, Chlb of Oak leaves. 2- Studying the effect of the slope aspect on leaf pigment content.

\section{MATERIALS AND METHODS}

\subsection{Description of the site and trees:}

Pirmus village is located about $15 \mathrm{~km}$ to the southeast of Duhok city (36.803238 deg. latitude, $43.150866 \mathrm{deg}$. longitudes). The study area is hilly and its elevation is between $714-736 \mathrm{~m}$ above mean sea level. The trees heights were between $4-5 \mathrm{~m}$. The location of each site was registered by using a GPS (global positioning system) receiver. Fig-1 shows the research site.

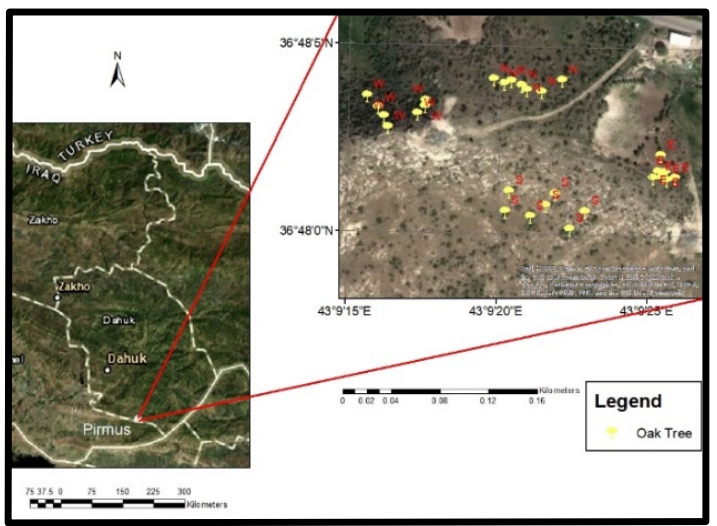

Figure-1 the research site

\subsection{Collecting of leaf samples:}

a. 28 Oak trees (to be in the safety side statistically) were selected from the area on May 6, 2019, and every seven trees were selected from each of the four main slope aspects NSEW as it is shown in fig-2.

b. Well-developed branches were carefully selected from each tree and two leaf samples were collected from the top of trees, so the total number of leave samples will be 56 .

c. The samples were sealed in polyethylene bags to maintain their moisture content and then stored in an ice cooler. (Arellano et al. 2017).

d. The height of each tree was measured by using a $5 \mathrm{~m}$ surveying staff and the position of each tree was measured by using a GPS (global positioning system) receiver.

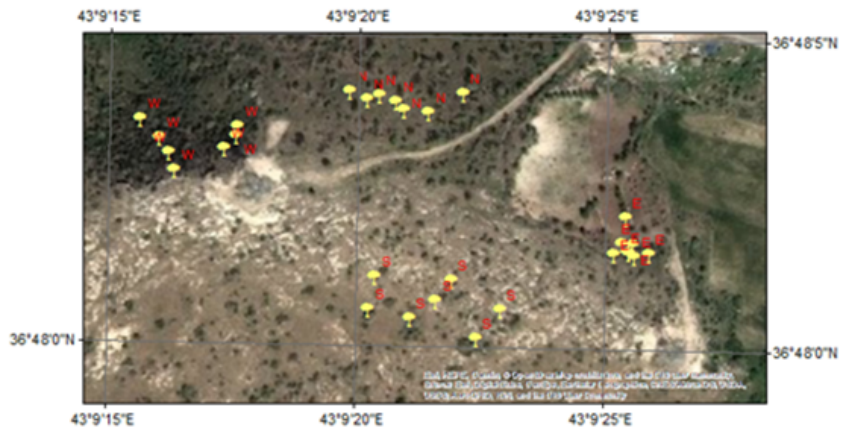

Figure-2 the samples locations

\subsection{Acquiring the leaves reflectance spectra:}

Both the technique and the instrument that we used were new and they are used for the $1^{\text {st }}$ time in Kurdistan region. The reflectance spectra for each of the 56 leaf samples were acquired in the laboratory by using ASD FieldSpec 3 spectroradiometer about three hours after collecting time. This instrument acquires continuous spectra from $350 \mathrm{~nm}$ to 2500 $\mathrm{nm}$; its spectral resolution is $3 \mathrm{~nm}$ at $700 \mathrm{~nm}$ and $10 \mathrm{~nm}$ at 1400 - $2100 \mathrm{~nm}$. Also, white reference (spectralon panel) corrections were used for calibration (Roger M. McCoy, 2005). The overall average spectrum for each tree was calculated from 2 leaf samples (fig-3).

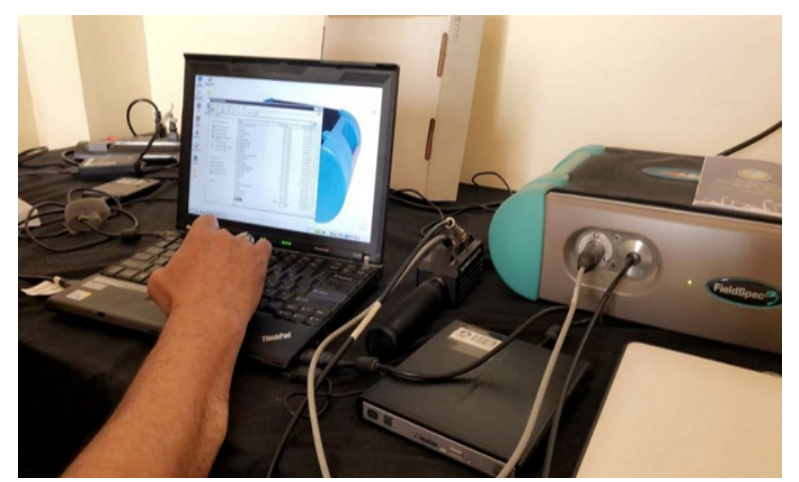

Figure.3 the (ASD) FieldSpec 3 spectroradiometer

\subsection{Pigment analysis in the laboratory:}

a. A $0.25 \mathrm{gm}$ of the leaf samples of each tree was used to prepare an extract of (Chla and Chlb) by using absolute ethanol 3 hours after the reflectance acquiring (Sims, 2002).

b. A $15 \mathrm{ml}$ ethanol was added for each sample and after 72 hours the solution was completed to $45 \mathrm{ml}$ by adding ethanol (Wintermans and DeMots, 1965).

c. The maximum absorbance (A) of each solution was determined spectrophotometrically at two wavelengths (649 and $665 \mathrm{~nm})$. The concentration of each pigment was determined twice by using the 6705UV/VIS (Total pharmacy supply).

d. The total chlorophyll content of leaves (mg chl. gm-1 fresh weight) was calculated according to Knudsen method (Wintermans and DeMots 1965) by using the following equations:

$\mathrm{mg}$ chla/ml solution $=(13.7)(\mathrm{A} 665 \mathrm{~nm})-(5.76) \quad$ (A 649 $\mathrm{nm}) . .(1)$

$\mathrm{mg}$ chlb/ml solution $=(25.8)($ A $649 \mathrm{~nm})-(7.6)($ A 665 $\mathrm{nm}) . .(2)$

$\mathrm{Chl}=(\mathrm{chla})+(\mathrm{chlb}) \ldots$

\subsection{Calculating the correlation coefficient:}

The researcher used the Statgraphics 18 - X64 software to calculate the coefficient of correlation and $\left(\mathrm{R}^{2}\right)$ between the spectroscopy reflectance results of leaves against the laboratory pigments analysis results. 


\section{RESULTS AND DISCUSSION}

3.1 Reflectivity curves and chlorophyll concentration:

In the beginning, it is worth mentioning that no research was found that talks about the hyperspespectroscopy of Oak trees or for any other trees in Kurdistan Region because it is the $1^{\text {st }}$ time that this new technique is used in this area. All the papers in the world present works about mixed broad leaf forests. In the Kurdistan region, we may find some but they do not talk about spectral features but about the traditional methods.

Figure- 4 shows some of the trees leave reflectivity curves for each of the four slope aspects NESW. Each figure shows the curves of two leaves that belong to one tree. The two curves show a minimum difference in reflectivity which means that the two leaves are identical. We concentrate on the chlorophyll absorption bands in the red spectrum (665 and $649 \mathrm{~nm})(\mathrm{Pu}$, 2017).
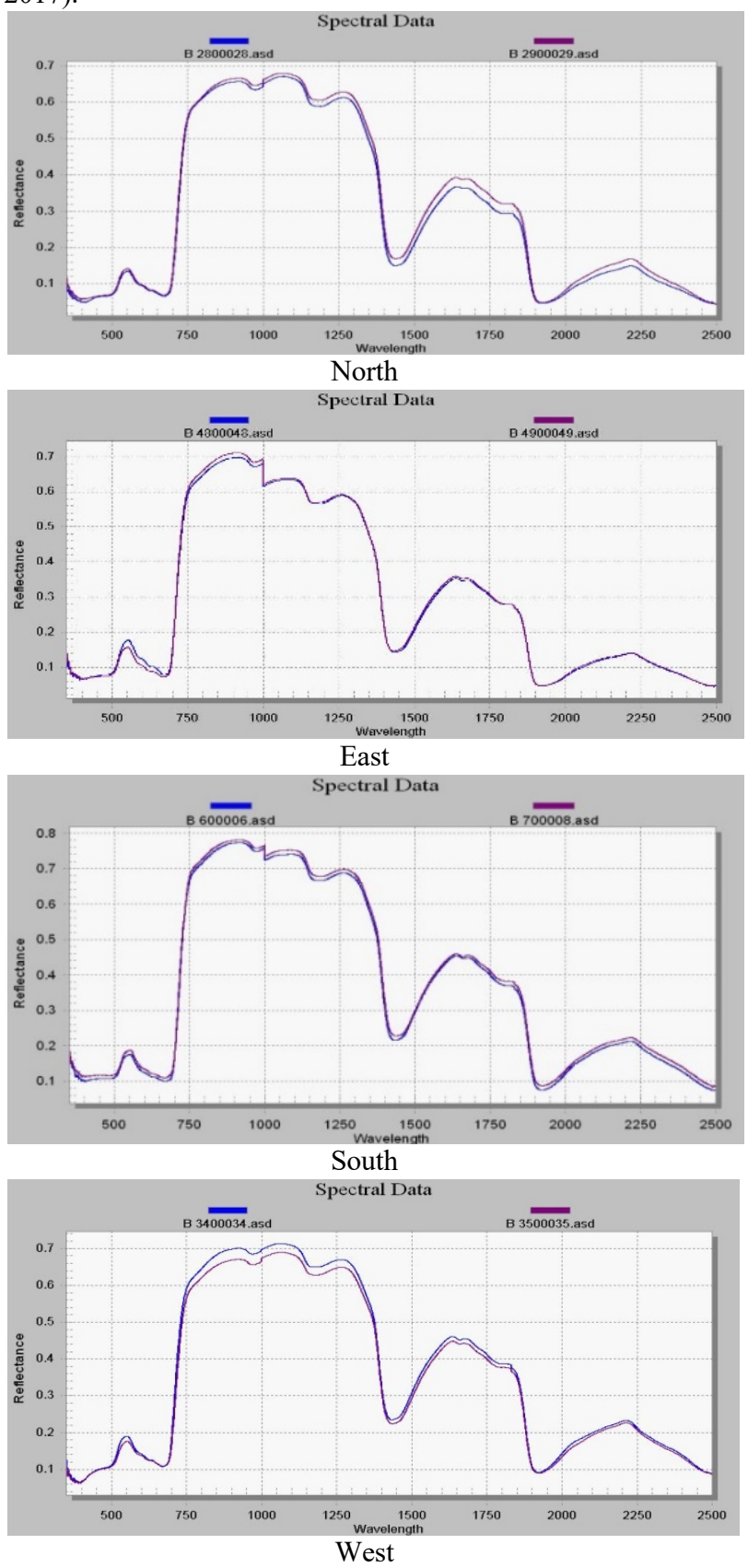

Figure- 4 some of the reflectivity curves of the 4 slope aspects
Table-1 shows the results of reflectivity and leaf chlorophyll concentrations that were measured in the laboratory at each of the wavelengths 665 and $649 \mathrm{~nm}$. It also shows the mean reflectivity percentage that the researcher got from the reflectivity curves. The $\mathrm{R}^{2}$ that computed by the Statgraphics 18 - X64 software between the chlorophyll concentrations and reflectivity shows that $\mathrm{R}^{2}$ for Chla (at $665 \mathrm{~nm}$ ) and Chlb (at $649 \mathrm{~nm}$ ) for the overall 28 trees show the moderately strong relationship $(73.165,48.089)$ alternatively. The standard errors were $0.0913355,0.0512682$ ) alternatively which are close to zero which indicates that the predicted values are close to the real values.

The content of each of Chla, Chlb and the total Chl were calculated by using equations $1,2 \& 3$ mentioned previously. The results in tab-2 show that the content of Chla ranges between $13.9352-20.41468 \mathrm{mg} / \mathrm{gm}$. which is near the range that Toma 2015 found in here research $(1.543-20.698 \mathrm{mg} / \mathrm{gm})$ and the total chl was between $13.86508-22.37706 \mathrm{mg} / \mathrm{gm}$ which it is within the range that Toma found $(2.156-27.344 \mathrm{mg} / \mathrm{gm})$.

Table-2 also shows the mean leave Chla content for each of the four slope aspects NESW; they were 15.86, 15.001, 16.145, and $15.663 \mathrm{mg} / \mathrm{gm}$. alternatively. The highest value belongs to the south slope aspect. This is because of the longest exposure to the sun light during the day which means more active photosynthesis (Diana K., 2018). The Chlb content does not have the same order as we saw in Chla, the mean value for each of the NESW aspects was 3.046, 3.458, 3.366, and 3.074 alternatively. This is because Chla is more effective than Chlb in the red band (Biology, 2019).

\subsection{The effect of slope aspects on reflectivity and chlorophyll concentration:}

The results depicted that the $\mathrm{R}^{2}$ of Chla for each of the four slope aspects NESW were 34.112, 79.805, 94.113 and 82.8547 alternatively. The last three aspects ESW results show strong relationships among the variables, while it is only (34.112) for the north aspect. This is directly related to the zenith angle (at the $36 \mathrm{~N}$ latitude which is about $76.5 \mathrm{deg}$.), the north-facing slopes receive less direct sunlight than south-facing slopes (Williams D, 2018). Accordingly, the north aspect will bias the overall $\mathrm{R}^{2}$ of the 28 trees (it is only 73.165 for the four aspects), so if we exclude it from the other aspects, the total $\mathrm{R}^{2}$ of the rest three aspects will be 84.7264 . This is agreed with Croft, et.al (2014) who found that the broad leave trees in Haliburton Forest- Ontario Canada show a strong relationship with leaf chlorophyll at the red band with an $\mathrm{R}^{2}$ between $0.7-0.80$. Also, the coefficient of correlation $(\mathrm{R})$ that the researcher found ranged between (-0.8833 to -0.970123$)$ which is more than the result that Qiu and others (2019) found in the visible spectrum $(R=-0.81)$ for broadleaf trees samples taken from different China fields.

Most of the standard error values of chla for the four slope aspects SNEW were $(0.0419621,0.143789,0.0685267$, 0.100696 ) alternatively and are close to zero which indicates that the predicted values are close to the real values. The $\mathrm{R}^{2}$ of Chlb at $649 \mathrm{~nm}$ for the four slope aspects NESW were $49.498,63.25,76.99$ and 74.34 alternatively. It is obvious like in Chla that each of the four aspects except the north one shows a strong relationship with the variables. The reason for that is the same as in Chla (Williams D, 2018). The same thing is true for the standard error values of Chlb, they were $0.028614,0.0222774,0.0235722$, and 0.0161366 alternatively. 
Table-1 the reflectivity and chlorophyll concentration for the red band

\begin{tabular}{|c|c|c|c|c|c|}
\hline Aspects & Name & $\begin{array}{c}\text { Chla conc. at } 665 \mathrm{~nm} \\
665 \mathrm{~nm}\end{array}$ & Refl. at $665 \mathrm{~nm}$ & Chlb conc. at $649 \mathrm{~nm}$ & Refl. at $649 \mathrm{~nm}$ \\
\hline \multirow{7}{*}{ S } & b6 & 1.494 & 8 & 0.54 & 9.5 \\
\hline & b14 & 1.596 & 7 & 0.538 & 10.5 \\
\hline & b16 & 1.266 & 10 & 0.547 & 9 \\
\hline & b18 & 1.186 & 9.95 & 0.521 & 9 \\
\hline & $\mathrm{b} 20$ & 1.47 & 7.85 & 0.53 & 8 \\
\hline & $\mathrm{b} 22$ & 1.21 & 9.6 & 0.5 & 8.1 \\
\hline & b24 & 1.428 & 8 & 0.58 & 10.5 \\
\hline \multirow{7}{*}{$\mathrm{N}$} & $\mathrm{b} 26$ & 1.527 & 7.65 & 0.531 & 9 \\
\hline & $\mathrm{b} 28$ & 1.4 & 7.15 & 0.448 & 11 \\
\hline & $\mathrm{b} 30$ & 1.248 & 8.15 & 0.52 & 10 \\
\hline & $\mathrm{b} 32$ & 1.24 & 9 & 0.53 & 7 \\
\hline & b34 & 1.39 & 11 & 0.583 & 6.5 \\
\hline & $\mathrm{b} 36$ & 1.698 & 6.15 & 0.462 & 10.5 \\
\hline & $\mathrm{b} 38$ & 1.493 & 6.85 & 0.6 & 10.5 \\
\hline \multirow{7}{*}{$\mathrm{E}$} & $\mathrm{b} 40$ & 1.13 & 10 & 0.471 & 10 \\
\hline & $\mathrm{b} 42$ & 1.266 & 8.85 & 0.48 & 9.5 \\
\hline & $\mathrm{b} 44$ & 1.427 & 7.7 & 0.491 & 8.5 \\
\hline & $\mathrm{b} 46$ & 1.384 & 7.25 & 0.432 & 9 \\
\hline & b48 & 1.204 & 8.65 & 0.578 & 9.2 \\
\hline & $\mathrm{b} 50$ & 1.531 & 7.5 & 0.462 & 11 \\
\hline & $\mathrm{b} 52$ & 1.257 & 8.85 & 0.734 & 6.5 \\
\hline \multirow{7}{*}{ W } & b54 & 1.444 & 7.5 & 0.551 & 8 \\
\hline & $\mathrm{b} 56$ & 1.678 & 7.5 & 0.556 & 9.3 \\
\hline & $\mathrm{b} 58$ & 1.307 & 8.25 & 0.635 & 6.5 \\
\hline & $\mathrm{b} 60$ & 1.096 & 9.35 & 0.48 & 8.5 \\
\hline & $\mathrm{b} 62$ & 1.448 & 8.3 & 0.382 & 10.5 \\
\hline & $\mathrm{b} 64$ & 1.274 & 9.2 & 0.497 & 9.5 \\
\hline & b66 & 1.718 & 6.9 & 0.542 & 11.7 \\
\hline
\end{tabular}

Table-2 the values of each of Chla, Chlb and the total Chl for the red band

\begin{tabular}{|c|c|c|c|c|c|c|c|}
\hline & $665 \mathrm{~nm}$ & $649 \mathrm{~nm}$ & Chla mg/gm & mean of Chla mg/gm & $\begin{array}{l}\text { Chlb } \\
\mathrm{mg} / \mathrm{gm}\end{array}$ & mean of Chlb mg/gm & Total chl mg/gm \\
\hline \multirow{7}{*}{ S } & 1.494 & 0.54 & 17.3574 & \multirow{7}{*}{16.145} & 2.5776 & \multirow{7}{*}{3.366} & 19.935 \\
\hline & 1.596 & 0.538 & 18.76632 & & 1.7508 & & 20.51712 \\
\hline & 1.266 & 0.547 & 14.19348 & & 4.491 & & 18.68448 \\
\hline & 1.186 & 0.521 & 13.24724 & & 4.4282 & & 17.67544 \\
\hline & 1.47 & 0.53 & 17.0862 & & 2.502 & & 19.5882 \\
\hline & 1.21 & 0.5 & 13.697 & & 3.704 & & 17.401 \\
\hline & 1.428 & 0.58 & 16.2228 & & 4.1112 & & 20.334 \\
\hline \multirow{7}{*}{$\mathrm{N}$} & 1.527 & 0.531 & 17.86134 & \multirow{7}{*}{15.86} & 2.0946 & \multirow{7}{*}{3.046} & 19.95594 \\
\hline & 1.4 & 0.448 & 16.59952 & & 0.9184 & & 17.51792 \\
\hline & 1.248 & 0.52 & 14.1024 & & 3.9312 & & 18.0336 \\
\hline & 1.24 & 0.53 & 13.9352 & & 4.25 & & 18.1852 \\
\hline & 1.39 & 0.583 & 15.68492 & & 4.4774 & & 20.16232 \\
\hline & 1.698 & 0.462 & 20.04276 & & 1.5174 & & 21.56016 \\
\hline & 1.493 & 0.6 & 16.9981 & & 4.1332 & & 21.1313 \\
\hline \multirow{7}{*}{$\mathrm{E}$} & 1.13 & 0.471 & 12.76804 & \multirow{7}{*}{15.001} & 3.5638 & \multirow{7}{*}{3.458} & 16.33184 \\
\hline & 1.266 & 0.48 & 14.5794 & & 2.7624 & & 17.3418 \\
\hline & 1.427 & 0.491 & 16.72174 & & 1.8226 & & 18.54434 \\
\hline & 1.384 & 0.432 & 16.47248 & & 0.6272 & & 17.09968 \\
\hline & 1.204 & 0.578 & 13.16552 & & 5.762 & & 18.92752 \\
\hline & 1.531 & 0.462 & 18.31358 & & 0.284 & & 18.59758 \\
\hline & 1.257 & 0.734 & 12.99306 & & 9.384 & & 22.37706 \\
\hline
\end{tabular}




\begin{tabular}{|c|c|c|c|c|c|c|c|}
\hline \multirow{7}{*}{ W } & 1.444 & 0.551 & 16.60904 & \multirow{7}{*}{15.663} & 3.2414 & \multirow{7}{*}{3.074} & 19.85044 \\
\hline & 1.678 & 0.556 & 19.78604 & & 1.592 & & 21.37804 \\
\hline & 1.307 & 0.635 & 14.2483 & & 6.4498 & & 20.6981 \\
\hline & 1.096 & 0.48 & 12.2504 & & 4.0544 & & 16.3048 \\
\hline & 1.448 & 0.382 & 11.74628 & & 2.1188 & & 13.86508 \\
\hline & 1.274 & 0.497 & 14.59108 & & 3.1402 & & 17.73128 \\
\hline & 1.718 & 0.542 & 20.41468 & & 0.9268 & & 21.34148 \\
\hline
\end{tabular}

Table- 3 shows the results of fitting a linear model to describe the relationship between reflectance and laboratory results for the $649 \mathrm{~nm}$ band, and figure-5 shows the fitted model and its equation. Since the P-value in the analysis of variance (ANOVA) table is less than 0.05 , there is a statistically significant relationship between $649 \mathrm{~nm}$ Reflectance and laboratory chlorophyll values at the $95.0 \%$ confidence level.

Table-3 Analysis of the variance of $649 \mathrm{~nm}$

\begin{tabular}{|l|l|l|l|l|l|}
\hline Source & Sum of Squares & Df & Mean Square & F-Ratio & P-Value \\
\hline Model & 0.056003 & 1 & 0.056003 & 21.31 & 0.0001 \\
\hline Residual & 0.0604539 & 23 & 0.00262843 & & \\
\hline Total (Corr.) & 0.116457 & 24 & & & \\
\hline
\end{tabular}

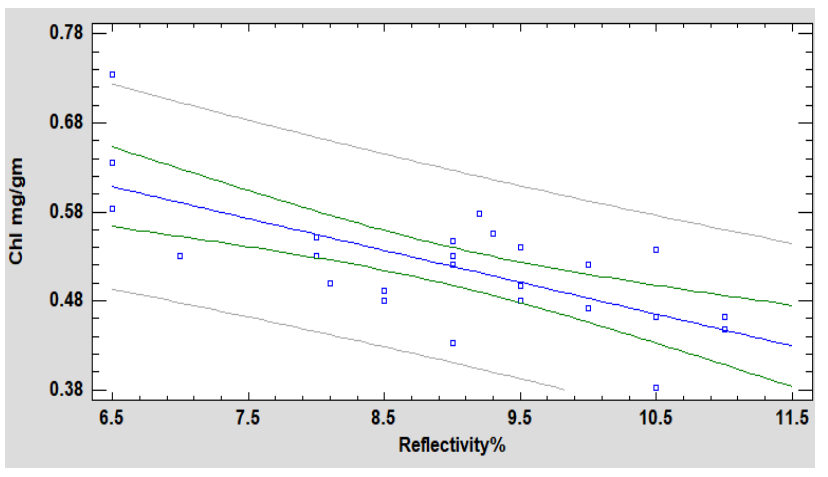

Figure-5 the fitted model of the $649 \mathrm{~nm}$ band

The fitted model is:

Chlb mg/gm $=0.841014-0.0358159 *$ Reflectivity\%

Table- 4 shows the results of fitting a linear model to describe the relationship between $\mathrm{Chl} \mathrm{mg} / \mathrm{gm}$ and Reflectivity at $665 \mathrm{~nm}$ and figure- 6 shows the fitted model and its equation. Table-4 Analysis of the variance of $665 \mathrm{~nm}$

\begin{tabular}{|l|l|l|l|l|l|}
\hline Source & $\begin{array}{l}\text { Sum of } \\
\text { Squares }\end{array}$ & $D f$ & Mean Square & F-Ratio & P-Value \\
\hline Model & 0.568627 & 1 & 0.568627 & 68.16 & 0.0000 \\
\hline Residual & 0.208555 & 25 & 0.00834218 & & \\
\hline Total (Corr.) & 0.777182 & 26 & & & \\
\hline
\end{tabular}

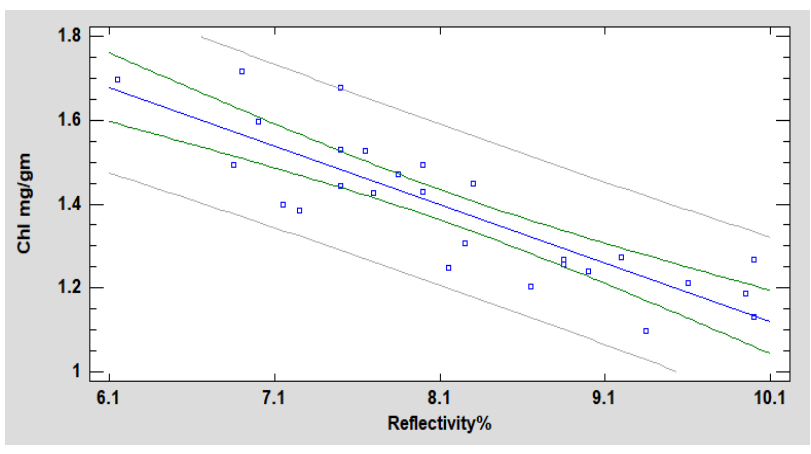

Figure- 6 the fitted model of the $665 \mathrm{~nm}$ band

The fitted model is:

Chla $\mathrm{mg} / \mathrm{gm}=2.53464-0.140245 *$ Reflectivity $\%$

Since the P-value in the ANOVA table is less than 0.05, there is a statistically significant relationship between
Reflectivity and Ch mg/gm. (RA-4) at the $95.0 \%$ confidence level.

\section{CONCLUSION:}

According to the current results, it is very obvious that the ASD FieldSpec 3 spectroradiometer is the quite efficient and un destructive tool that can be used for Quercus Aegilops chlorophyll estimation at 665 and $649 \mathrm{~nm}$. The results show that the $\mathrm{R}^{2}$ of Chla (at $665 \mathrm{~nm}$ ) and Chlb (at $649 \mathrm{~nm}$ ) for the whole trees show a strong relationship between the variables $(73.165,48.089)$ alternatively with low standard error $(0.0913355,0.0512682)$ which indicates that the predicted values are close to the real values.

Besides that, the instrument shows the capability of distinguishing the differences in leaf chlorophyll content among the different slope aspects. The order of the $\mathrm{R}^{2}$ values from the highest to the lowest values for $665 \mathrm{~nm}$ was $94.113>79.805$ and $82.8547>34.112$ which is an alternative to South $>$ east and west $>$ north. We can find similar results for the $649 \mathrm{~nm}$; it was $76.99>63.25$ and $74.34>49.498$. Besides that the highest average leave Chl content was found in the south slope aspect, it was $15.795 \mathrm{mg} / \mathrm{gm}$. at $665 \mathrm{~nm}$ while in the $649 \mathrm{~nm}$ show no differences among the ratios. In the future, these results would be considered to be as a leader for those coming researches which are going to use the same technique and instrument that we used.

\section{REFERENCES}

Arellano P, Tansey K, Balzter H, Boyd DS (2017) Field spectroscopy and radiative transfer modeling to assess impacts of petroleum pollution on biophysical and biochemical parameters of the Amazon rainforest. Environ Earth Sci (2017) 76:217

Charle' ne Guillot1 and Thomas Lecuit1,2013, Adhesion Disengagement Uncouples Intrinsic and Extrinsic Forces to Drive Cytokinesis in Epithelial Tissues, 1Aix-Marseille Universite' , CNRS UMR 7288, IBDM, Campus de Luminy, Case 907, 13288 Marseille Cedex 09, France.

Croft, H., Chen, J., M., Zhang, Y., and Simic, A. (2014). The applicability of empirical vegetation indices for determining leaf chlorophyll content over different leaf and canopy structures,

Croft, H., Chen, J., M., Zhang, Y., and Simic, A. (2013). Modeling leaf chlorophyll content in broadleaf and needle leaf canopies from ground, CASI, Landsat TM 5 and 
MERIS reflectance data. Remote Sens. Environ. 133, $128-140$.

Davies KM (ed). (2004). Plant pigments and their manipulation. Annual plant reviews, Vol. 14. Oxford, UK: Blackwell Publishing.

Qiu, F., Chen, J., Croft, H., Li, J., Zhang, Q., Zhang, Y., and Ju, W. (2019). Retrieving Leaf Chlorophyll Content by Incorporating Variable Leaf Surface Reflectance in the PRO-SPECT Model.

Filella, I., Serrano, I., Serra, J., and Penuelas, J. (1995).Evaluating wheat nitrogen status with canopy reflectance indices and discriminant analysis, Crop Science, 35, 14001405 .

Gamon JA, Surfus JS (1999). Assessing leaf pigment content and activity with a reflectometer. Department of Biology and Microbiology, California State University Los Angeles, 5151 State University Drive, Los Angeles, CA 90032, USA

Hendry, G.A.F., Houghton, J.D., and Brown, S.B. (1987). The degradation of chlorophyll-A biological enigma, New Phytologist, 107, 255-302.

Kumar V. (2016) Hyper spectral Remote Sensing SPIE APRS 2016 Pre Symposium Tutorial, New Delhi, 110075 .

Li Y, He N, Hou J, Xu L, Liu C, Zhang J, Wang Q, Zhang X and Wu X (2018) Factors Influencing Leaf Chlorophyll Content in Natural Forests at the Biome Scale. Front. Ecol. Evol. 6:64. doi: 10.3389/fevo.2018.00064

Marcus Borengasser, et.al, 2008, Hyperspectral Remote Sensing: Principles and Applications, CRC Press, Taylor \& Francis Group, 6000 Broken Sound Parkway NW, Suite 300 Boca Raton, FL 33487.

Måren, I.E., Karki, S., Prajapati, Ch., Yadav, R.K., Shrestha, B. (2015). Facing north or south: Does slope aspect impact forest stand characteristics and soil properties in a semiarid trans-Himalayan valley. Journal of Ari Environments. 121. 10.1016/j.jaridenv.2015.06.004.

Merzlyak, M.N., Gitelson, A.A., Chivkunova, O.B., and Rakitin, V.Y. (1999). Non-destructive optical detection of leaf senescence and fruit ripening, Physiologia Plantarum, 106, 135-141.
Michael B. F., et. al., (1990). Solar Electricity Handbook.

Moore, R., et. al, 1995, Light Absorption for Photosynthesis, W.H. Freeman and company, san Francisco.

Nagata, N., Tanaka, R., Satoh, S., and Tanaka, A. (2005). Identification of a vinyl reductase gene for chlorophyll synthesis in Arabidopsis thaliana and implications for the evolution of Prochlorococcus species. Plant Cell 17, 233-240. doi: 10.1105/tpc.104.027276

$\mathrm{Pu}, \mathrm{R}$. (2017). Hyperspectral remote sensing fundamentals and practice. CRC Press Taylor \& Francis Group 6000 Broken Sound Parkway NW, Suite 300 Boca Raton, FL 33487-2742

Roger M. McCoy, 2005, Field Methods in Remote Sensing, THE GUILFORD PRESS New York London, A Division of Guilford Publications, Inc. 72 Spring Street, New York, NY 10012

ROSENBERG, N.J., B.L. BLAD, and S.B. VERMA. 1983. Microclimate-the biological environment. John Wiley and Sons, Inc., New York, New York.

Sims DA, Gamon JA (2002) Relationships between leaf pigment content and spectral reflectance across a wide range of species, leaf structures and developmental stages. Remote Sens Environ81:337-354 doi:10.1016/S0034-4257(02)00010-X

Toma, R. (2015). Induction of chromosomal polyploidy and early evaluation of valonia oak (Quercus aegilops L.) Transplants. (Thesis submitted to University of Duhok).

Wald, L (2018). Basics in solar radiation at earth surface. MINES ParisTech, PSL Research University O.I.E. Observation, Impacts, Energy Center Sophia Antipolis, France

Wolken, J. J., Mellon, A. D., and Greenblatt, C. L. (1955) Environmental factors affecting growth and chlorophyll synthesis in euglena. I. physical and chemical. II. the effectiveness of the spectrum for chlorophyll synthesis. J. Eukaryot. Microbiol. 2, 8996.

Zhou, G. S. (2003). Effect of water stress on photochemical activity of chloroplast from wheat. J. Beijing Agric. College $18, \quad 188-190$ doi: $10.3969 /$ j.issn.10023186.2003.03.008 